\title{
The Meta Energy of Dark Energy
}

\author{
Mohamed S. El Naschie \\ Department of Physics, University of Alexandria, Alexandria, Egypt \\ Email: Chaossf@aol.com
}

Received 16 March 2014; revised 16 April 2014; accepted 23 April 2014

Copyright (C) 2014 by author and Scientific Research Publishing Inc. This work is licensed under the Creative Commons Attribution International License (CC BY). http://creativecommons.org/licenses/by/4.0/

(c) (i) Open Access

\section{Abstract \\ This short note gives philosophical background for the rationale behind regarding the dark ener- gy of the cosmos as meta energy.}

\section{Keywords}

Positivistic Philosophy; Heidegger Meta Physics; Quantum Mechanics; Dark Energy; Relativity; Cantorian Set the Ory; Reichenbach Scientific Philosophy

\section{Introduction}

Prof. J. Ayer left his position as the Provost of University College, London University (Ayer, 1952, 1954, 1985) just as I became a Ph.D. post graduate student in engineering. However, I was able to learn a few things being a great adherent to his rejection of "metaphysics" and his enthusiasm for Reichenbach scientific positivistic philosophy (Ayer, 1952, 1954, 1985; Heidegger, 2006; Heisenberg, 1969; Reichenbach, 1951). However I started very early to realize that there is also a great deal of limitation in "positivism” which I learn about first from W. Heisenberg and particularly his book “Der Teil und das Ganze” (Heisenberg, 1969) and later on from encountering C.F. von Weizäcker. Ayer pointed out a misconception regarding metaphysics which persisted due to the writing of M. Heidegger (Heidegger, 2006). Metaphysics is not something higher than physics but a term simply used by Aristotle in his book to point out that after the chapters dealing with physics, now comes the next "meta" chapter on things after dealing with physics (Ayer, 1952, 1954, 1985). Nevertheless the common praxis is to look at metaphysics as the "foundation" of fundamental concepts in physics such as space and time. In fact in England metaphysics is what we call more often natural philosophy. G. Cantor, the founder of transfinite set theory, uses metaphysics as identical to pure mathematics and mathematical philosophy. He said for instance “ohne ein quintchen Metaphysics lässt sich meine überzeugung keine exacte wissenshaft treiben”. We will examine a proposed connection between dark energy and “meta” physics.

\section{Analysis}

In what follows we will look at the fundamental problem connected to what we call dark energy. Dark energy 
may be called meta energy because it is the manifestation of a meta spacetime which is there only in not being there in the ordinary meaning of the word. Dark energy comes from the empty set in an incredible and direct way. The empty set is given in transfinite set theory via a simple realization of K-theory due to the work of first, A. Conne and Penrose and second, the present author.

$$
D(-1) \equiv\left(-1, \phi^{2}\right) ; \quad \phi=(\sqrt{5}-1) / 2
$$

where -1 is the Menger-Urysohn deductive topological dimension and -1 is the Hausdorff dimension corresponding to the just mentioned topological dimension. The pseudo five dimensional volume of $D(-1)$ is given by (El Naschie, 2013c, 2014d, 2014e)

$$
\operatorname{Vol}_{(5)} D(-1)=5 \phi^{2} .
$$

Together with the zero set

$$
D(O)=(O, \phi)
$$

and

$$
\operatorname{Vol}_{(5)} D(O)=\phi^{5}
$$

they form the world sheet of string theory:

$$
\operatorname{Vol}_{(5)}(\text { total })=5 \phi^{2}+\phi^{5}=2
$$

The relative density is therefore

$$
\operatorname{Vol}_{(5)}(D(-1))=\frac{\operatorname{Vol}_{(5)} D(-1)}{\operatorname{Vol}_{(5)}(\text { total })}=\frac{5 \phi^{2}}{2}
$$

and

$$
\operatorname{Vol}_{(5)}(D(O))=\frac{\operatorname{Vol}_{(5)} D(\mathrm{O})}{\operatorname{Vol}_{(5)}(\text { total })}=\left(\frac{\phi^{5}}{2}\right)
$$

The corresponding Einstein reduced energy density is thus (El Naschie, 2013a, 2013b, 2013c)

$$
E(\text { ordinary })=\left(\frac{\phi^{5}}{2}\right) \mathrm{mc}^{2}
$$

and

$$
E(\text { dark })=\left(\frac{5 \phi^{2}}{2}\right) \mathrm{mc}^{2}
$$

exactly as derived in previous publications (El Naschie, 2013a, 2013b, 2013c, 2014e). We note that the rational approximation of Equation (9) is $E(D)=\mathrm{mc}^{2}(21 / 22)$ while the rational approximation of Equation (8) is the by now well known extended Einstein equation (El Naschie, 2013a, 2013b, 2013c, 2014d, 2014e, 2014f, 2014g, 2014h; Marek-Crnjac, 2013)

$$
E(O)=\mathrm{mc}^{2} / 22
$$

It is also important that our theory is inclusive as opposed to exclusive in the sense that they unite the opposed view point in a manner not dissimiar to Hegel's dialectic philosophy. Thus our spacetime is both open and closed topologically, i.e. clopen (El Naschie, 2013a, 2013b, 2013c, 2014d, 2014e, 2014f, 2014g, 2014h; MarekCrnjac, 2013). In addition it is infinite and finite by virtue of Klein-Penrose hyperbolic fractal tiling of 't HooftSusskind holographic boundary. It is a true coincidencia opposotorium forming a higher reality but in an exact mathematical meaning (El Naschie, 2013a, 2013b, 2013c, 2014d, 2014e, 2014f, 2014g, 2014h; Marek-Crnjac, 2013). 


\section{Conclusion}

Looking at the wider philosophical picture of physics and cosmology it seems to be beneficial for understanding the deep meaning of modern cosmological observations to regard dark energy as meta energy, despite the reservations prevailing among the current scientific mainstream against "meta” physics.

\section{References}

Ayer, A. J. (1952). Language, Truth and Logic. New York: Dover Publications.

Ayer, A. J. (Editor) (1954). Logical Positivism. West Port: Greenwood Press.

Ayer, A. J. (1985). More of My Life. Oxford: Oxford University Press.

El Naschie, M. S. (2013a). A Unified Newtonian-Relativistic Quantum Resolution of the Supposedly Missing Dark Energy of the Cosmos and the Constancy of the Speed of Light. International Journal of Modern Nonlinear Theory and Application, 2, 43-54. http://dx.doi.org/10.4236/ijmnta.2013.21005

ElNaschie, M. S. (2013b). Determining the Missing Dark Energy of the Cosmos from a Light Cone Exact Relativistic Analysis. Journal of Physics, 2, 18-23.

El Naschie, M. S. (2013c). Nash Embedding of Witten’s M-Theory and the Hawking-Hartle Quantum Wave of Dark Energy. Journal of Modern Physics, 4, 1417-1428. http://dx.doi.org/10.4236/jmp.2013.410170

El Naschie, M. S. (2014d). Why E Is Not Equal to $\mathrm{mc}^{2}$. Journal of Modern Physics, in Press.

El Naschie, M. S. (2014e). Logarithmic Running of 't Hooft-Polyakov Monopole to Dark Energy. International Journal of High Energy Physics, 1, 1-5.

El Naschie, M. S. (2014f). Pinched Material Einstein Spacetime Produces Accelerated Cosmic Expansion. International Journal of Astronomy and Astrophysics, 4, 80-90. http://dx.doi.org/10.4236/ijaa.2014.41009

El Naschie, M. S. (2014g). Capillary Surface Energy Elucidation of the Cosmic Dark Energy-Ordinary Energy Duality. Open Journal of Fluid Dynamics, 4, 15-17. http://dx.doi.org/10.4236/ojfd.2014.41002

El Naschie, M. S. (2014h). Calculating the Exact Experimental Density of the Dark Energy in the Cosmos Assuming a Fractal Speed of Light. International Journal of Modern Nonlinear Theory and Application, 3, 1-5. http://dx.doi.org/10.4236/ijmnta.2014.31001

Heidegger, H. (2006). Sein und Zeit. Tubingen: Niemeyer.

Heisenberg, W. (1969). Der Teil und das Ganze. Munich: Pieper.

Marek-Crnjac, L. (2013). Cantorian Space-Time Theory-The Physics of Empty Sets in Connection With Quantum Entanglement and Dark Energy. Saarbrücken: Lambert Academic Publishing.

Reichenbach, H. (1951). The Rise of Scientific Philosophy. Oakland, CA: University of California Press. 